\title{
LA IMPLEMENTACIÓN DE LA LEY DE MEMORIA HISTÓRICA EN LA CIUDAD DE LA CORUÑ ${ }^{1}$
}

\author{
The Implementation of the Historical Memory Law in the City of Corunna
}

\author{
Pedro Vázquez-Miraz \\ pvasquez@utb.edu.co \\ Universidad Tecnológica de Bolívar. Colombia \\ Fecha de recepción: 11/07/2020 \\ Fecha de aceptación: 02/11/2020
}

Resumen: Se presenta en el siguiente artículo un estudio exploratorio sobre la aplicación en una ciudad española de tamaño medio de la denominada Ley de la Memoria Histórica (creada en el año 2007). A través de la heráldica y la numismática, al estudiar la evolución de los escudos oficiales de España (2a república, franquismo y monarquía constitucional), se analizó la simbología del franquismo y la implementación de esta legislación en la ciudad de La Coruña en base a un análisis documental de las actas del ayuntamiento durante el período 2007-2019. La conclusión principal del trabajo fue que la puesta en práctica de este código legislativo, además de haberse basado en símbolos de ambigua catalogación, varió de forma significativa en base al partido gobernante que estuviera en el poder de la urbe (Partido Socialista Obrero Español, Partido Popular y Marea Atlántica); evidenciándose así que los parámetros políticos primaron por encima de los históricos y los jurídicos.

Palabras clave: memoria histórica; guerra civil española; franquismo; heráldica; numismática.

Abstract: The following article presents an exploratory study about the implementation in a middle-sized city of the so-called Historical Memory Law (established in 2007). Through heraldry and numismatics, considering the evolution of the coats of arms of Spain (2nd Republic, Francoism and constitutional monarchy), it was analyzed Francoism symbolism and the execution of the law in the

${ }^{1}$ Agradecemos encarecidamente la ayuda recibida de D. Pablo José Alegre y Doña María Fernanda Medina a la hora de maquetar el material gráfico del presente documento. 
city of Corunna based on a documentary analysis of the city council acts in 2007-2019 lapse. The main conclusion was that the practical implementation of this legal code, apart from being based on symbols of ambiguous cataloging, varied significantly based on the ruling party at the moment (Partido Socialista Obrero Español, Partido Popular y Marea Atlántica); making clear that way that the political parameters prevailed over history and law.

Keywords: historical memory; Spanish civil war; Francoism; heraldry; numismatic.

Sumario: 1. Introducción. 2. La creación de la Ley de Memoria Histórica. 3. Contexto histórico del ámbito geográfico, objeto de estudio. 4. Metodología. 5. Resultados. 5.1. Los aportes de la heráldica y la numismática y las contradicciones de la Ley de Memoria Histórica. 5.2. La implementación de la Ley de Memoria Histórica en la ciudad de La Coruña. 6. Conclusiones. 7. Referencias bibliográficas.

\section{INTRODUCCIÓN}

El concepto de memoria histórica es estudiado desde diferentes perspectivas académicas (Velasco, 2017), abundando en la disciplina histórica española las acusaciones de revisionismo en función de la ideología política de diferentes autores (Balfour, 2006). Así, la proliferación de estos estudios en España (Sanmartín, 2007) es un aspecto científico que puede explicarse por la presencia de tres factores fundamentales: la demanda de verdad, justicia y reparación de víctimas en democracias que sufrieron guerras y/o dictaduras, la búsqueda de las raíces de la propia sociedad y la necesidad de un valor fijo que sea un pilar ante el mundo cambiante actual (Aguilar-Forero, 2018). Si bien el concepto de memoria histórica se puede asumir como un término de comunicación política (Vázquez-Miraz, 2020), entendido como «la lista de los acontecimientos cuyo recuerdo conserva la historia naciona» (Halbwachs, 1995, p. 212).

Barros (2014) recalcaría que los modelos teóricos de memoria histórica son dos principalmente: el alemán y el argentino. El primero fue creado a partir de los juicios de Núremberg al finalizar la II Guerra Mundial (paso judicial para lograr la desnazificación en Alemania), prohibiéndose de manera legal el uso de símbolos del régimen nacionalsocialista; mientras que el segundo tuvo su origen en la resistencia pacífica de las Abuelas y Madres de la Plaza de Mayo y fue más laxo que el anterior al no proponer leyes punitivas que coartasen la libertad de los partidarios del autodenominado Proceso de Reorganización Nacional.

La guerra civil española y la dictadura franquista fueron los dos acontecimientos históricos del siglo Xx más traumáticos que ha sufrido España (Ruiz-Vargas, 2006) ya que además de los daños materiales y las pérdidas humanas, por su intrínseco carácter civil, el sufrimiento fue más severo. Situación que se agravaría en la posguerra al consolidar el régimen del general Franco una rígida separación entre vencedores y vencidos (Casanova, 2008). 
Habiendo asumido que la situación en España se acerca más al modelo argentino que al alemán, en esta nación europea los postulados ideológicos extremistas fueron asumidos por individuos que le dieron carácter de verídico, científico y riguroso a las falsas informaciones históricas (Moreno-López, 2018). Buen ejemplo de esto sería la buena acogida en la sociedad española de la denominación de "políticamente incorrecto», un simple eufemismo de intencionalidad persuasiva (Sánchez-García, 2018).

Es por lo dicho que consideramos que toda nación democrática (como la española) requiere mantener un difícil equilibrio entre la defensa de la libertad de expresión sobre hechos del pasado y la persecución de las difamaciones y ataques a los más vulnerables. Como bien explica Teruel $(2018$, p. 15):

En un momento de crisis, cuando vuelve a observarse en Europa el ascenso de grupos sociales y de partidos políticos con discursos intolerantes que cuestionan los valores democráticos de convivencia, se hace más evidente la peligrosidad del denominado "discurso del odio» y se reclaman respuestas frente al mismo. Sin embargo, la necesidad de enfrentarse a este tipo de discursos ha mostrado también una preocupante tendencia restrictiva de la libertad de expresión que obliga a descender al porqué y a las razones últimas de su protección constitucional. Hay que afrontar no solo el problema de proteger la libertad, sino también el de justificarla.

Desde posturas progresistas, la sociedad española demandaría la necesidad de reparar moral y económicamente a las víctimas de la represión franquista y recuperar la memoria histórica (Escudero, 2018). Por ello, los estudios históricos serían los más adecuados para conseguir esta labor académica al centrarse en el rol de las víctimas y fomentar una auténtica reconciliación, alcanzar una mejor convivencia futura (Escudero, 2013) y manejar el concepto de verdad (Escudero, 2018). Término último que nosotros consideramos vacío de contenido y de fuerte carga emocional.

Por ende, nuestra hipótesis de investigación consistió (previamente estudiada la Ley de Memoria Histórica) en haber realizado un estudio descriptivo de los escudos del franquismo, puesto que nos hemos basado en el supuesto de que la propia Ley de Memoria Histórica no determinó con pertinente claridad qué símbolos y personajes históricos ensalzan la dictadura. De esta manera se ha pretendido discernir cómo se implementó esta medida legislativa en una ciudad española que tuvo tres consistorios políticos diferentes seguidos en el período 2007-2019 como lo fue La Coruña.

\section{LA CREACIÓN DE LA LEY DE MEMORIA HISTÓRICA}

La Ley $52 / 2007$, de 26 de diciembre, por la que se reconocen y amplían derechos y se establecen medidas en favor de quienes padecieron persecución o violencia 
durante la guerra civil y el gobierno de Franco $^{2}$ pretendió cumplir este objetivo, al entrar en vigor durante el primer mandato del presidente socialista José Luis Rodríguez Zapatero (Meyenberg y Hernández, 2015). Una medida legislativa aprobada por los principales sectores políticos progresistas y rechazada por la oposición conservadora de la nación ibérica, siendo el objetivo fundamental de esta ley el de...

...contribuir a cerrar heridas todavía abiertas en los españoles y a dar satisfacción a los ciudadanos que sufrieron, directamente o en la persona de sus familiares, las consecuencias de la tragedia de la Guerra Civil o de la represión de la Dictadura. Quiere contribuir a ello desde el pleno convencimiento de que, profundizando de este modo en el espíritu del reencuentro y de la concordia de la Transición, no son sólo esos ciudadanos los que resultan reconocidos y honrados sino también la Democracia española en su conjunto (Ley 52/2007, p. 3).

El ámbito más progresista entendió que una carencia fundamental de la Ley 52/2007 fue que el propio concepto de memoria histórica estaba ausente por completo (Escudero, 2018) mientras el conservadurismo asumió que esta medida legal iba a polarizar la sociedad española y abrir las viejas heridas de la guerra civil (Paniagua, 2018). Sin ninguna intención de entrar en debates políticos, está claro que el aspecto más polémico de esta ley fue el tratamiento de los símbolos y monumentos públicos de la guerra civil y el franquismo, pues estos serían los principales motivos de discordia en la política española a pesar de la exposición explícita de motivos de la Ley de Memoria Histórica:

El espíritu de reconciliación y concordia, y de respeto al pluralismo y a la defensa pacífica de todas las ideas, que guio la Transición, nos permitió dotarnos de una Constitución, la de 1978, que tradujo jurídicamente esa voluntad de reencuentro de los españoles, articulando un Estado social y democrático de derecho con clara vocación integradora.

El espíritu de la Transición da sentido al modelo constitucional de convivencia más fecundo que hayamos disfrutado nunca y explica las diversas medidas y derechos que se han ido reconociendo, desde el origen mismo de todo el período democrático, en favor de las personas que, durante los decenios anteriores a la Constitución, sufrieron las consecuencias de la guerra civil y del régimen dictatorial que la sucedió (Ley 52/2007, p. 1).

${ }^{2}$ Cuatro puntos son los que dan cuerpo al artículo 15 de la susodicha ley, la cual hace referencia a la representación y elementos asociados con ese período histórico, obligando esta normativa a que las administraciones públicas deberían retirar «escudos, insignias, placas y otros objetos o menciones conmemorativas de exaltación, personal o colectiva, de la sublevación militar, de la Guerra Civil y de la represión de la Dictadura» (Ley 52/2007, p. 8), so pena de medidas coercitivas como la retirada de ayudas y subvenciones. El Valle de los Caídos, por sus características religiosas y su enorme simbología asociada al franquismo (Valiente, 2018), contaría con un artículo propio en la Ley de Memoria Histórica (Artículo 16). 


\section{CONTEXTO HISTÓRICO DEL ÁMBITO GEOGRÁFICO, OBJETO DE ESTUDIO}

A diferencia de lo sucedido a nivel estatal donde la reinstauración de la democracia supuso la continuidad en el poder político de las élites del pasado (Márquez, 1993), la primera corporación municipal democrática de la ciudad de La Coruña se caracterizó por poseer un enfoque rupturista con el pasado franquista al ser elegido alcalde el nacionalista gallego Domingos Merino (1979-1981). Si bien la inestabilidad política de su consistorio hizo que su mandato fuera de breve duración al ser gobernada posteriormente la villa por el conservador Joaquín López Menéndez (1981-1983) y durante décadas por el Partido Socialista Obrero Español (19832011); habiéndose destacado en esta última etapa la labor del munícipe socialdemócrata y de profundas convicciones católicas Francisco Vázquez, alcalde durante los años 1983-2006.

La alcaldía de Francisco Vázquez, uno de los líderes socialistas más importantes de la España de su época por sus logros políticos, sería denominada popularmente como el vazquismo. Una corriente política de corte populista y nacionalista españolista que aglutinaba las tendencias del socialismo gallego y elementos de la democracia cristiana a través de la impronta localista y el liderazgo carismático de su líder ${ }^{3}$. Fue durante su largo mandato cuando se inició un proceso paulatino por el cual en el callejero urbano de la ciudad aparecieron los primeros nombres ligados al republicanismo español. Medidas que se acrecentaron con su sucesor, el socialista Javier Losada (2006-2011) al haberse realizado los primeros trabajos académicos, compilaciones de elementos icónicos de la dictadura y estudios analíticos sobre la simbología franquista que perduraban en la ciudad para su futura eliminación.

Este proceso se paralizaría durante el gobierno conservador de Carlos $\mathrm{Ne}$ greira (2011-2015) para ser retomado con ímpetu por el consistorio de Marea Atlántica dirigido por Xulio Ferreiro (2015-2019). Este último mandato y otros similares (como los de otras ciudades gallegas de la provincia como Santiago de Compostela y Ferrol) estaban vinculados intrínsecamente con sectores políticos críticos con la propia Transición y la historiografía tradicional, al considerar estos colectivos que el paso a la democracia debió haber sido rupturista y la legitimidad del estado español fundamentarse en la Constitución republicana de 1931 (Rueda, 2016).

${ }^{3}$ Véase como ejemplo de esta tendencia localista-populista el férreo rechazo a la oficialidad del topónimo en gallego de la ciudad (A Coruña) en aras de una supuesta defensa de la cooficialidad de los términos en gallego y español (Martínez-Hidalgo, 2006). Una polémica lingüística que desaparecería por completo al abandonar Francisco Vázquez la alcaldía y renunciar su partido a esa directriz. 


\section{METOdOLOGÍA}

En primer lugar, se buscó analizar el trasfondo histórico y político de la Ley de Memoria Histórica por medio de un estudio comparado de la evolución histórica de los escudos de la nación española, entendidos estos como símbolos de poder (Valle-Porras, 2017), la legislación que soportó a estos cambios como elementos históricos (Galende y García-Ruipérez, 2003) y la aplicación práctica de esta ley en la ciudad de La Coruña.

De forma más concreta, por medio de un análisis histórico de corte comparativo entre las épocas republicana, franquista y monárquica se ha revisado la evolución histórica del escudo de España para así poder interpretar los significados y valores actuales de los símbolos que identifican a España en relación con la Ley de Memoria Histórica, fijándonos también en los escudos nacionales representados en las monedas de los años 70 y 80 como elementos históricos de gran valor. La heráldica y la numismática son subdisciplinas históricas que tienen una gran relación con el ámbito del derecho, al analizar ambas, signos del pasado que transmitían a la población información sobre el poder constituido y su legitimidad (Huidobro, 2015).

Se examinaron las principales actuaciones relacionadas con la aplicación de esta ley en la ciudad de La Coruña durante el período 2007-2019 a través de las actas públicas de este ayuntamiento, diferenciándose tres épocas: los gobiernos del Partido Socialista Obrero Español (2007-2011), Partido Popular (2011-2015) y Marea Atlántica (2015-2019). Adicionalmente se ha inspeccionado el listado de símbolos franquistas conformados por escudos, placas, monumentos y grupos de viviendas elaborada por el experto Manuel Monge. Un catálogo presentado por la Comisión pola Recuperación da Memoria Histórica da Coruña a finales del año $2018^{4}$.

\section{RESULTADOS}

El estudio de la Ley de Memoria Histórica y de los símbolos políticos más relevantes del régimen autocrático de Franco ha pretendido dilucidar la existencia de contradicciones en la misma ley y su implementación práctica. Si bien la ley es clara respecto a los aspectos temporales que está legislación abarca (18 de julio de 1936 - 20 de noviembre de 1975), no lo sería tanto acerca de qué símbolos exaltarían a la guerra civil y a la dictadura franquista (y cuales no).

${ }^{4}$ Comisión por la Recuperación de la Memoria Histórica de La Coruña (traducción al español). Según Monge, al finalizar 2018, existían 106 elementos de simbología franquista en el municipio de La Coruña, de los cuales 74 son propiedad del municipio y 32 de un ente público de rango superior. 
5.1. Los aportes de la heráldica y la numismática y las contradicciones de la Ley de Memoria Histórica

Aunque ya iniciada la guerra, por el Decreto 77, de 29 de agosto (1936), los rebeldes habían aceptado la bandera roja y gualda como elemento contrario al régimen republicano simbolizando este símbolo durante el régimen franquista, «junto con el himno, el escudo y el reconocimiento de un solo idioma, la unidad del Estado autoritario» (Aguilera y Vernet, 1993, p. 149), el escudo heráldico del nuevo estado tardaría en definirse un par de años, habiéndose adaptado finalmente una versión moderna del escudo de los Reyes Católicos para legitimarse con el pasado (MazaZorrilla, 2014). El motivo de esa decisión quedaría plasmado en el decreto del 2 de febrero de 1938:

Ningún conjunto heráldico más bello y más puramente español que el que presidió, en el reinado de los Reyes Católicos, la consumación de la Reconquista, la fundación de un Estado Fuerte e Imperial, el predominio en Europa de las armas españolas, la unidad religiosa, el descubrimiento de un mundo nuevo, la iniciación de la inmensa obra misional de España, la incorporación de nuestra cultura al Renacimiento.

El águila que en él figura no es la del Imperio germánico, al cabo exótica en España, sino la del evangelista San Juan, que, al cobijar bajo sus alas las armas españolas, simboliza la adhesión de nuestro Imperio a la verdad católica, defendida tantas veces con sangre de España; en él figuran, además, el haz de flechas y el yugo, entonces, como ahora, emblema de unidad y de disciplina (Antequera, 2009, p. 19).

Este escudo, de trece cuarteles o el abreviado de cinco (Fig. 1 y 2), fue un fuerte alegato político pues en el ideario colectivo del franquismo el modelo histórico anhelado a imitar era la España imperial y la Castilla de Isabel I (Zorrilla, 2014), siendo sus símbolos más importantes el águila de San Juan, el yugo y las flechas. Elementos de los Reyes Católicos cuyo gobierno sería considerado para muchos historiadores como el inicio del estado español moderno (Moreno, 2017) y para otros un simple mito nacionalista como otros más (Aguilera y Vernet, 1993; Vázquez-Miraz, 2020). El yugo y las flechas se mantendrían con la cruz de Borgoña en el escudo oficial del rey Juan Carlos I (1975-2014) al haber realizado cambios menores en el escudo franquista que lo designaba como príncipe de España (véase el Decreto 814/1971).

Nuevamente este escudo sufriría ligeras modificaciones (Fig. 2) en el año 1945 (véase el decreto de 11 de octubre) y cambios drásticos en 1977 (por medio del Real Decreto 1511/77, de 21 de enero), para ser sustituido por el vigente escudo monárquico vigente desde 1981, por medio de la Ley 33/1981, sancionada el 5 de octubre de ese mismo año (Fig. 3). Un elemento muy similar al escudo de 1868 del Gobierno provisional surgido a la caída de la monarquía de Isabel II y al escudo de la II República. 

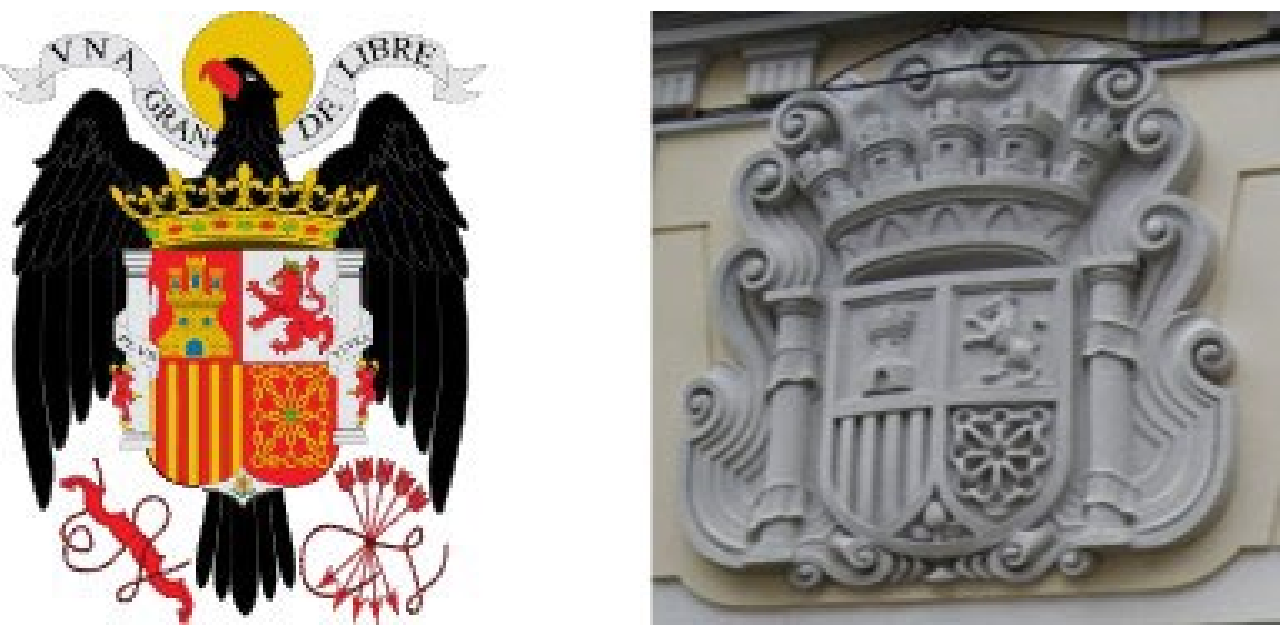

Figura 1. Escudo heráldico de la España sublevada (modelo "abreviado» de 1938) en contraste con el escudo republicano (1931-1939); presente en el CEIP Cidade Vella de la ciudad de La Coruña. Adaptación propia.
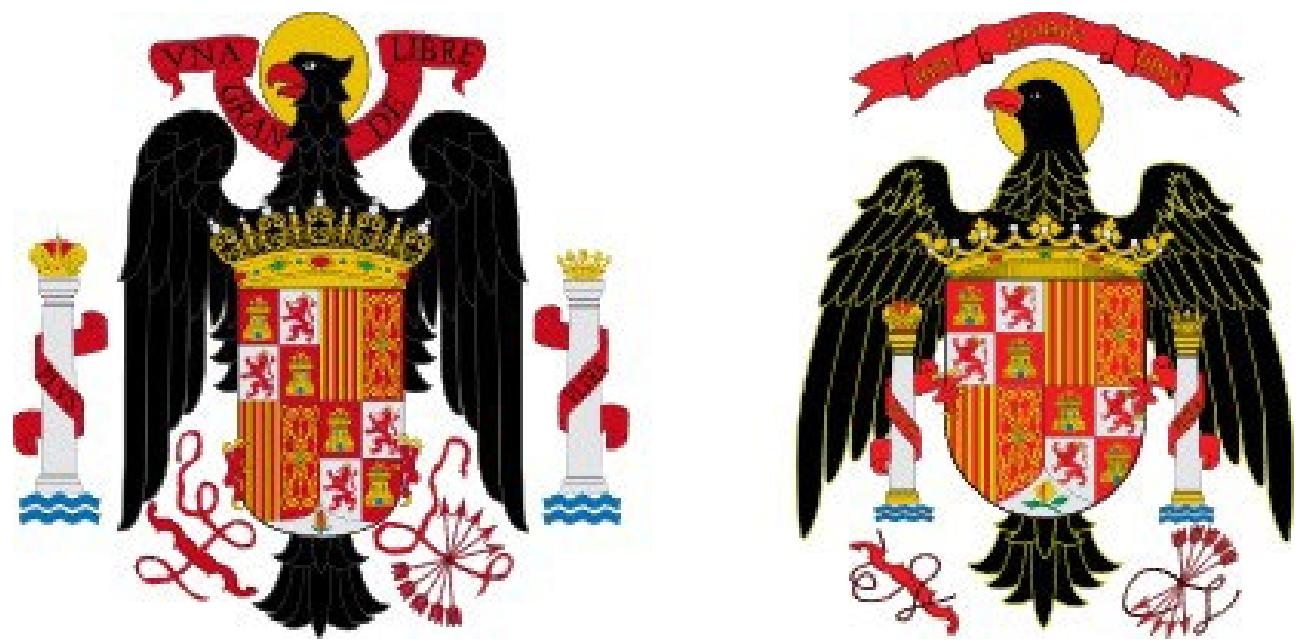

Figura 2. Escudos heráldicos de España. Modelos completos de 1945 y 1977. Adaptación propia

Aplicando la Ley de Memoria Histórica, es irrefutable que los escudos de 1938 y 1945 ensalzarían el totalitarismo y deberían se erradicados, aunque estos se presentaran únicamente con el blasón y sin otros ornamentos como el águila de San Juan y/o la corona imperial. Más compleja sería la decisión al respecto con el modelo del año 1977 pues es evidente que este escudo es una evolución de los anteriores, pero también es un claro nexo entre la dictadura y los primeros años del reinado juancarlino y la democracia española (un período temporal no contemplado por la Ley de Memoria Histórica). 
Por consiguiente, el analizar los escudos franquistas es algo complejo pues estos de facto quedarían legitimados al haber aparecido en elementos representativos del estado español ya en plena democracia. Por ejemplo, el modelo de 1945 estaba en las monedas de 1 peseta de la primera serie numismática del reinado de Juan Carlos I (emitida durante los años 1976-1980), mientras que el modelo de 1977 lucía en las piezas de 1 peseta que conmemoraba el Mundial de Fútbol de 1982 (serie emitida en tres series consecutivas durante los años 1980-1982).

De todas formas, en la Transición también se evidenció un alejamiento paulatino de la monarquía con el régimen anterior (Medina, 2014) al introducir en las primeras acuñaciones (además del escudo nacional) la corona real (moneda de 25 ptas.) o el escudo de su reinado (en las monedas de 5 y 50 pesetas, descrito este en párrafos anteriores), para aparecer el vigente escudo nacional en el segundo sistema monetario (las denominadas emisiones M. Coronada) a partir del año 1982 (De Francisco-Olmos, 2005); si bien de manera anacrónica muchas monedas del franquismo (1, 5, 25 y 50 ptas.) mantuvieron el estatus de dinero de curso legal hasta finales del siglo XX.

\subsection{La implementación de la Ley de Memoria Histórica en la ciudad de La Coruña}

La ideología de cada corporación ha influido en el grado y modo en la que se implementó la Ley de Memoria Histórica en la ciudad de La Coruña. Después de revisar numerosas actas de los plenos municipales se determinó que los equipos políticos de partidos de ideología más progresista como la coalición de gobierno formada por el Partido Socialista Obrero Español - Bloque Nacionalista Galego encabezada por Javier Losada (2007-2011) y el gobierno en minoría de Marea Atlántica (2015-2019) fueron las alcaldías que mayores cambios han realizado en la simbología franquista de la ciudad apelando a la Ley de Memoria Histórica, en contraste con la política de no intervención que realizó el Partido Popular en su mandato (2011-2015) al haber mantenido las reformas de los anteriores equipos de gobierno pero sin promover más modificaciones.

Fue en la sesión plenaria del 7 de septiembre de 2009 cuando el pleno municipal de la ciudad adoptó tener conocimiento de un informe (elaborado ad hoc) por una comisión de expertos para la aplicación de la Ley 52/2007; habiéndose aprobado ese susodicho texto a excepción de la retirada de retratos de los alcaldes dentro de la sede de la alcaldía, alegándose el hecho (bastante debatible) de que esas pinturas no exaltaban a la dictadura y solo reflejaban la historia.

Los cambios más relevantes acerca de estos distintivos y su trato, en cumplimiento de la Ley de Memoria Histórica (y plasmados en los debates políticos del municipio durante los años 2007-2011) fueron dos actuaciones llevadas a cabo por este consistorio progresista, recibiendo por ello las críticas de la oposición conservadora. Estas modificaciones fueron el cambio del nombre del hospital público Juan Canalejo [político falangista coruñés apresado en Madrid antes de la guerra y ejecutado de 
forma extrajudicial en Paracuellos del Jarama (Fernández-Prieto, 2009; Ruiz, 2012)] por Complejo Hospitalario Universitario A Coruña (CHUAC) en el año $2008^{5}$ y la retirada de la estatua de José Millán Astray ${ }^{6}$ [fundador de la Legión Española originario de esta ciudad y célebre por su enfrentamiento dialéctico con Miguel de Unamuno en plena guerra civil Jensen, 1992)] en su plaza homónima en el año 2010.

De esta suerte se ha podido observar que la erradicación de la supuesta simbología franquista de la ciudad llevada a cabo por el equipo de Javier Losada fue, como mínimo un proceso muy gradual y paulatino que podría considerarse como contradictorio o paradójico. Ya que en el mismo momento en que se hacían o promovían los cambios mencionados se mantenían sendas direcciones de la urbe con los nombres de Juan Canalejo (calle) y Millán Astray (plaza), las cuales no fueron suprimidas en ese período de gobierno.

Por su parte, la alcaldía del Carlos Negreira (2011-2015), sustentada en una cómoda mayoría absoluta del Partido Popular, mantuvo en un segundo plano este debate político y apenas hizo modificaciones al respecto (no reponiendo por ejemplo la estatua de Millán Astray ${ }^{7}$ ). Se mantenía así un bajo perfil motivado por la búsqueda de una agenda política que beneficiara más a este partido ${ }^{8}$, justificándose éste siempre con el manido argumento de la existencia de prioridades más relevantes.

Fue en el mandato de Marea Atlántica (gobierno en minoría) donde más cambios se produjeron. Así fueron eliminados del callejero militares del bando sublevado como el general Sanjurjo (cambiado por Avenida de Oza), el general Mola (Calle Álvaro Cebreiro y Plaza de San Andrés ${ }^{9}$ respectivamente), el teniente general Gómez Zamalloa (ahora Costa da Unión), el teniente coronel Teijeiro (calle Filantropía) o el comandante Barja (calle Riazor). Además, se suprimieron calles en honor a meros fallecidos del bando sublevado (Gómez, 2009) como la Plaza de los Caídos (Plaza de la Concordia) o la Plaza del Castillo de Olite (Plaza Tornos).

${ }^{5}$ Modificación aprobada finalmente por el gobierno autonómico de Galicia.

${ }^{6}$ Honrar al fundador de este cuerpo militar no justificaría la aplicación de la Ley de Memoria Histórica, sí el entender a este personaje como partícipe de la sublevación contra la república española.

7 El ayuntamiento de coalición también retiró la distinción de «hijo predilecto» de Millán Astray, medida recurrida judicialmente por la familia del militar y que en un primer momento se logró la restitución de este honor (ya que para la jueza no se debía aplicar la Ley de Memoria Histórica). Una situación que la alcaldía de Carlos Negreira no pleiteó (pero sí la Comisión por la Recuperación de la Memoria Histórica). Finalmente, el Tribunal Superior de Justicia de Galicia le daría la razón al equipo de Javier Losada.

${ }^{8}$ Como mera suposición personal, creemos que a esta formación política no le interesaba presentarse como un partidario del mantenimiento de símbolos vinculados al franquismo y así no perder el voto centrista, pero de manera indirecta sí se apoyaba esta postura para mantener el apoyo del votante más derechista de corte españolista.

${ }^{9}$ Es interesante recordar que la cruz de San Andrés fue el símbolo por excelencia de la aviación franquista y que sigue vigente en el ejército del aire español. 
También fueron sustituidos genéricos rangos militares excepcionales del franquismo ${ }^{10}$ como alférez y sargento provisional (Avenida del Porto y Calle Alberto Datas Panero) y partidarios civiles que ayudaron a la represión como Salvador y Merino (Calle Ría del Burgo), Pepín Rivero (Calle de la Educación) o Arcadio Vilela Garate (Calle de la Cultura). Mención aparte hacemos de los ya citados Juan Canalejo (Calle del Socorro) y Millán Astray (Plaza de Las Atochas), pues en esta etapa política estos personajes desaparecieron del espacio público coruñés. Todos estos actos fueron entendidos por la propia alcaldía como eventos de reivindicación política en aras de la recuperación de una (probable) memoria robada.

El gobierno de Xulio Ferreiro decidió también enmendar la decisión del pleno de septiembre del 2009 al haber ordenado la retirada de los retratos de los dos primeros alcaldes del bando sublevado (José Fuciños Gayoso y Hernán Martín de Barbadillo Paúl) por su participación directa en fusilamientos de represaliados. Curiosamente se mantuvieron estos honores a otros alcaldes y personalidades del franquismo, destacando entre ellos a Alfonso Molina, regidor que tuvo una enorme popularidad durante su mandato (Martín, 2016) y que en la actualidad da nombre a la principal avenida de acceso a la ciudad o a Pedro Barrié de la Maza, empresario que se lucró con bienes y negocios industriales incautados a represaliados republicanos (Carmona, 2015), presente también en el callejero.

Por último, al examinar el listado de Monge del año 2018 (uno de los autores involucrados con el informe de expertos aprobado en el año 2009) sobre símbolos franquistas existentes en la ciudad de ese catálogo se ha comprobado que en el apartado de escudos, placas, monumentos y grupo de viviendas aparecieron personajes ya mencionados como Alfonso Molina y otros de gran relevancia como José Calvo Sotelo ${ }^{11}$. Sin embargo, volviendo al ámbito de la heráldica, fue muy llamativo que ni el escudo franquista de mayores proporciones de la ciudad (Fig. 3) ni otro similar en la Escuela Técnica y Superior de Náutica y Máquinas de la Universidad de A Coruña fueran identificados en este trabajo.

10 La erradicación de la anacrónica calle en honor a la División Azul (denominada ahora calle Antón Vilar Ponte) también se hizo en esa misma época. Se asume que ese nombre, más que ensalzar a la dictadura homenajearía a los soldados españoles que lucharon con el ejército nazi en la II Guerra Mundial. Un evento histórico no contemplado en la Ley 52/2007.

${ }^{11}$ Respecto el caso específico de este político derechista (de origen gallego) creemos que Monge (presidente de la CMRH y político del BNG en tiempos pasados) ha aplicado mal la Ley 52/2007, acercándose más a la damnatio memoriae romana (Vázquez-Miraz, 2020) al considerar franquista una placa del año 1927. En ella se mencionaba el agradecimiento de la ciudad por el apoyo de este político al proyecto de construcción de una cárcel durante su mandato como ministro de hacienda en la dictadura de Miguel Primo de Rivera. Se debe recordar que José Calvo Sotelo fue detenido irregularmente y asesinado el 13 de julio de 1936, siendo considerado por el franquismo como un protomártir de la autodenominada "cruzada nacional» (Langa, 2000). Interesante el hecho de que una institución educativa pública de la ciudad (dependiente de la Diputación Provincial) haya mantenido la denominación en honor a este político hasta abril del año 2021. 

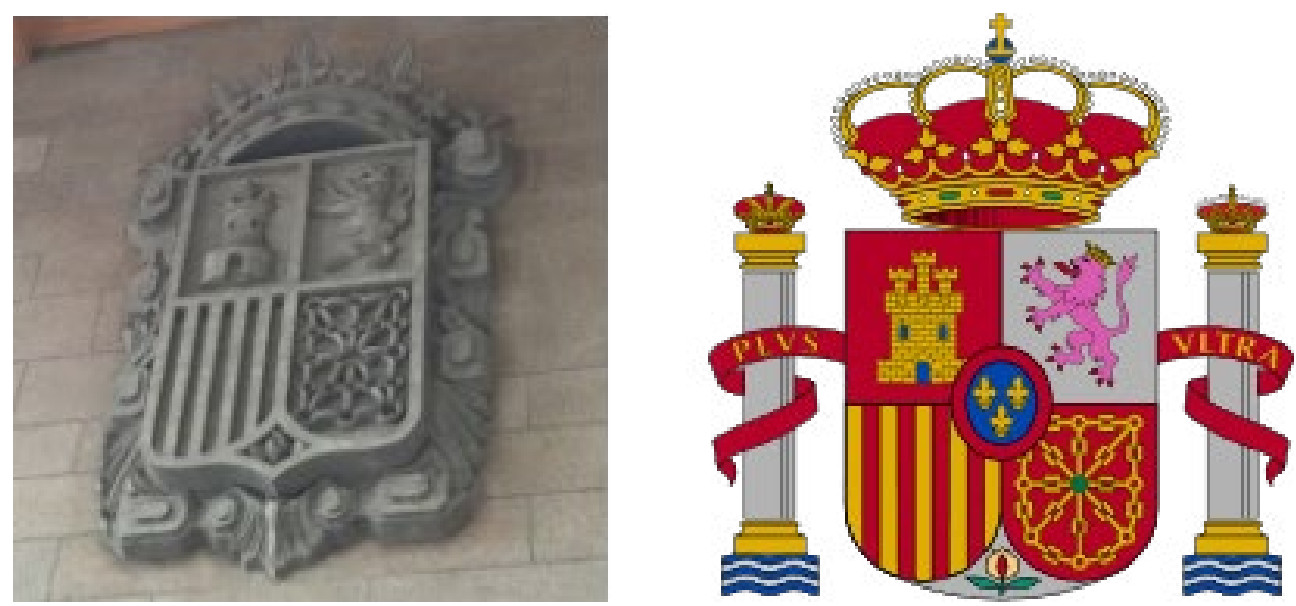

Figura 3. Escudo presente en la estación de ferrocarril de La Coruña y el escudo monárquico actual de España. Elaboración propia y adaptación de Medina (2014)

\section{CONCLUSIONES}

La heráldica y la numismática han proporcionado datos certeros que reflejarían la gran ambigüedad a la hora de definir elementos ensalzadores de la sublevación armada del 18 de julio, la guerra civil y la dictadura. Este objeto de estudio se complementaría con la revisión realizada de la implementación que hicieron las administraciones públicas de la Ley de Memoria Histórica respecto a la retirada de símbolos y monumentos de la época franquista en una ciudad media. Aunque seamos legos en la materia jurídica creemos que no es típico de las democracias avanzadas que una ley se aplique de formas tan extremas como las vistas en el presente documento. De todos modos, hemos sido conscientes de la dificultad de la interpretación política de esta ley, ya que como indicaron Avendaño-Castro y Enrique-Alfonso (2017) separar las nociones de víctima y de victimario es algo muy complejo.

Así pues, cada corporación política de La Coruña, en función de sus intereses políticos pero siempre justificándose en el cumplimiento de la Ley de Memoria Histórica o problemas técnicos y/o de presupuesto para hacer o no modificaciones, ha aplicado con mayor o menor diligencia esta normativa. Así pues, se ha evidenciado un mayor interés del Partido Socialista Obrero Español (cuando dirigía la villa en coalición con el Bloque Nacionalista Galego, en contraste con el vazquismo pasado) y de la Marea Atlántica por la modificación de los símbolos públicos de La Coruña frente a una absoluta inanición del Partido Popular.

En definitiva, en el contexto específico analizado, han primado más los aspectos políticos que los históricos y/o jurídicos en este tipo de decisiones relacionadas 
con la memoria histórica ${ }^{12}$. Aunque esta idea sea de amplio conocimiento, recalcamos que el implantar en la sociedad española visiones dicotómicas de la historia no sería lo más adecuado para lograr una sana convivencia y una auténtica reconciliación nacional. Por consiguiente, se ha considerado que la Ley de Memoria Histórica sería más un subterfugio para justificar variaciones de emblemas de la nación que un eficaz mecanismo para el respeto de las víctimas de la guerra civil y la dictadura.

Opinamos que, en un auténtico país avanzado, estas modificaciones se harían apelando al consenso y al sentido común, haciendo nuestras las palabras de Barros (1996) como respuesta a la superación de esta estéril posición de maniqueos extremos:

Es menester algo más: un debate que cierre la transición de la historiografía de la era franquista a una historiografía realmente democrática; donde la lucha de ideas historiográficas ha de estar por encima de las posiciones políticas, las cuales no debieran de ser un obstáculo para la convivencia y la colaboración entre los historiadores.

\section{REFERENCIAS BIBLIOGRÁFICAS}

Aguilar-Forero, Nicolás (2018). Políticas de la memoria en Colombia: iniciativas, tensiones y experiencias. Historia Crítica, 68, pp. 111-130. https://doi. org/10.7440/histcrit68.2018.06

Aguilera, C. y Vernet, J. (1993). Cuestiones simbólicas y Constitución Española. Revista de Estudios Políticos (Nueva Época), 79, pp. 139-160.

Antequera, J. J. (2009). Actualidad de la heráldica. Inercia y auge de la simbología municipal andaluza. Sevilla: Facediciones.

Avendaño-Castro, W. R. y Enrique-Alfonso, Ó. (2017). Conceptos fundamentales en la relación entre el poder simbólico y la violencia en Colombia. Revista Academia \& Derecho, 8(14), pp. 289-314. https://doi.org/10.18041/22158944/academia.14.1495

12 Debido a la calculada inactividad del gobierno conservador de Mariano Rajoy en esta temática (2011-2018) y a las constantes contradicciones, correcciones y modificaciones realizadas por el primer gobierno de Pedro Sánchez (2018-2020) ante el proceso de exhumar y posterior retirada del cadáver del dictador Francisco Franco del Valle de los Caídos en plena campaña electoral, creemos que la motivación política es la única que puede explicar estas conductas y no la búsqueda de la reconciliación nacional. 
Balfour, S. (2006). El revisionismo histórico y la Guerra Civil. Pasajes: Revista de pensamiento contemporáneo, 19, pp. 61-65.

Barros, Carlos (1996). Inacabada transición de la historiografía española. Bulletin d'Histoire Contemporaine de l'Espagne, 24, pp. 469-493.

Barros, C. (2014). Historia, memoria y franquismo. Historia Actual Online, 33, pp. 153-171.

Carmona, Z. (2015). Una empresa pequeña se hace grande: la Sociedad General Gallega de Electricidad y los orígenes de Fenosa. Revista de Historia Industrial, 24(n.o especial. Homenaje a Antonio Parejo), pp. 349-382.

Casanova, J. (2008). La historia social de los vencidos. Cuadernos de Historia Contemporánea, 30, pp. 155-163.

Decreto 77, de 29 de agosto de 1936, restableciendo la bandera bicolor roja y gualda, como bandera de España. Boletín Oficial de la Junta de Defensa Nacional de España, 14.

Decreto de 2 de febrero de 1938, por el que se crea el escudo de España. Boletín Oficial del Estado, 470.

Decreto de 11 de octubre de 1945, por el que se aprueba el Reglamento de Insignias, Banderas y Distintivos. Boletín Oficial del Estado, 285.

Decreto 814/1971 de 22 de abril de 1971, por el que se establece el guión y el estandarte que corresponden a S.A.R. el Príncipe de España don Juan Carlos de Borbón y Borbón. Boletín Oficial del Estado, 99.

De Francisco-Olmos, J. M.a (2005). Estudio de la tipología monetaria como documento propagandístico de la evolución política española (1975-2003). Revista General de Información y Documentación, 15(2), pp. 5-38.

Escudero, R. (2013). Jaque a la Transición: análisis del proceso de recuperación de la memoria histórica. Anuario de Filosofía del Derecho, 29, pp. 319-340.

Escudero, R. (2018). Memoria histórica e imperio de la ley: el poder judicial ante el derecho a la reparación de las víctimas del franquismo. Derechos y Libertades. I/ Época, 38, pp. 73-105. https://doi.org/10.14679/1057 
Fernández-Prieto, L. (2009). Actitudes sociales y políticas en la denominada recuperación de la memoria histórica. Galicia: el proyecto de investigación interuniversitario "Nomes e Voces». Pasado y Memoria. Revista de Historia Contemporánea, 8, pp. 131-157. https://doi.org/10.14198/PASAD02009.8.06

Galende, J. C. y García-Ruipérez, M. (2003). El concepto de documento desde una perspectiva interdisciplinar: de la diplomática a la archivística. Revista General de Información y Documentación, 13(2), pp. 7-35.

Gómez, J. A. (2009). Los acontecimientos de marzo de 1939 en Cartagena. El hundimiento del "Castillo de Olite», la mayor tragedia naval de la Guerra Civil. Revista de Historia Naval, 27, pp. 73-86.

Halbwachs, M. (1995). Memoria colectiva y memoria histórica. Revista Española de Investigaciones Sociológicas, 69, pp. 209-222. https://doi. org/10.2307/40183784

Huidobro, J. M. (2015). Numismática y heráldica en España. Madrid: Liber Factory.

Jensen, G. (1992). José Millán-Astray and the Nationalist "Crusade in Spain». Journal of Contemporary History, 27(3), pp. 425-447. https://doi. org/10.1177/002200949202700303

Langa, C. (2000). Los civiles, como víctimas de la guerra y de la propaganda. El ejemplo de la guerra civil española (1936-1939). Ámbitos, 3-4, pp. 181-194.

Ley $52 / 2007$, de 26 de diciembre de 2007 , por la que se reconocen y amplían derechos y se establecen medidas en favor de quienes padecieron persecución o violencia durante la guerra civil y la dictadura. Boletín Oficial del Estado, 310.

Márquez, G. (1993). La Transición local en Galicia: continuidad de las élites políticas del franquismo y renovación de los gobiernos locales» Revista de Estudios Políticos (Nueva Época), 80, pp. 39-119.

Martín, F. (2016). Alfonso Molina: el hombre de los Franco en Coruña. Anuario Brigantino, 39, pp. 155-172.

Martínez-Hidalgo, F. (2006). O discurso A Coruña / La Coruña: a política lingüística e os límites do consenso. Revista de Investigaciones Políticas y Sociológicas, 5(1), pp. 49-63. 
Maza-Zorrilla, E. (2014). El mito de Isabel de Castilla como elemento de legitimidad política en el franquismo. Historia y Política, 31, pp. 167-192.

Medina, J. (2014). La marca comercial como espejo de la comunicación heráldica. Tesis doctoral: Universitat Pompeu Fabra.

Meyenberg, Y. y Hernández, D. (2015). Los alcances de un nuevo proyecto socialdemócrata La primera legislatura de José Luis Rodríguez Zapatero. Revista Mexicana de Ciencias Políticas y Sociales, 60(224), pp. 163-186. https://doi. org/10.1016/S0185-1918(15)30007-6

Moreno, F. J. (2017). El franquismo y la apropiación del pasado: el uso de la historia, de la arqueología y de la historia del arte para la legitimación de la dictadura. Madrid: Editorial Pablo Iglesias.

Moreno-López, B. (2018). El uso de la pseudociencia y la experimentación en las nuevas tendencias de comunicación publicitaria como recurso persuasivo. Revista Latina de Comunicación Social, 73, pp. 1428-1443.https://doi. org/10.4185/RLCS-2018-1315

Paniagua, P. (2018). Una forma calculada de herir la Memoria Histórica. Repercusión en Twitter de las declaraciones de los diputados del Partido Popular Pablo Casado y Rafael Hernando. Hispania Nova, 16, pp. 394-416. https://doi. org/10.20318/hn.2018.4042

Real decreto 1511/1977, de 21 de enero de 1977, por el que se aprueba el Reglamento de Banderas y Estandartes, Guiones, Insignias y Distintivos. Boletín Oficial del Estado, 156.

Rueda, J. C. (2016). El candado del 78: Podemos ante la memoria y la historiografía sobre la ruptura democrática» Historia Contemporánea, 53, pp. 725-751. https://doi.org/10.1387/hc.16742

Ruiz, J. (2012). El terror rojo. Barcelona: Espasa.

Ruiz-Vargas, J. M.a (2006). Trauma y memoria de la Guerra Civil y la dictadura franquista. Hispania Nova. Revista de Historia Contemporánea, 6.

Sánchez-García, F. J. (2018). Los marcos conceptuales de la interdicción política: tabúes y eufemismos persuasivos en España después del 15-M. Tonos Digital. Revista Electrónica de Estudios Filológicos, 35(2). 
Sanmartín, I. (2007). Nuevas tendencias en la historiografía española. Cuadernos de Estudios Gallegos, 54(120), pp. 305-325. https://doi.org/10.3989/ceg.2007. v54.i120.31

Teruel, G. (2018). Cuando las palabras generan odio: límites a la libertad de expresión en el ordenamiento constitucional español. Revista Española de Derecho Constitucional, 114, pp. 13-45. https://doi.org/10.18042/cepc/redc114.01

Valiente, G. (2018). Juan de Ávalos y el Valle de los Caídos: un escultor republicano para un monumento franquista. Historia Digital, 18(31), pp. 130-150.

Valle-Porras, J. M. (2017). La investigación sobre heráldica española, con especial atención a la Edad Moderna. Estado de la cuestión. Revista de Historiografía, 27, pp. 315-340. https://doi.org/10.20318/revhisto.2017.3976

Vázquez-Miraz, P. (2020). Representación de la historia de España por medio de la filatelia. Estudio de los sellos diseñados por Gallego y Rey. Panta Rei. Revista Digital de Ciencia y Didáctica de la Historia, 14(1), 89-107. https://doi. org/10.6018/pantarei.444341

Velasco, C. (2017). Historia y memoria: un mismo combate. Aportaciones epistemológicas de Historia a Debate a las controversias acerca de la memoria histórica. Memorias: Revista Digital de Arqueología e Historia desde el Caribe, 33, pp. 120-141. 